poor Papuan culture can be will be well appreciated by reading $\mathrm{Mr}$. Wollaston's description of these people, yet they use paddles for propelling their canoes, whereas it is very doubtful whether the Toro on the Bensbach River, forming the boundary of British and Netherlands New Guinea, know paddles at all, and they certainly propel their canoes in deep water by using their long bamboo punting poles as if they were paddles.

Everywhere the expedition, which was clearly too large, was hampered by a lack of knowledge of the country; a little preliminary surveying in a launch would have obviated this difficulty. Indeed, in spite of the money, some, alas! public, lavished on the expedition, the organisers seem to have made up their minds to ignore the experience of previous explorers. Much might have been done by the expedition had it been better planned, but Mr. Wollaston's book, which must be taken as the official account of the expedition, and candidly admits the blunders made, shows that the somewhat scanty results attained are not in any way due to lack of energy or morale on the part of the members of the party, and every reader will join in wishing Mr. Wollaston good luck and all success on his second expedition to the country towards which he is now speeding.

C. G. S.

\section{THE FIRST INTERNATIONAL EUGENICS} CONGRESS.

$\mathrm{T}^{\mathrm{T}}$ is the general feeling of those who attended 1 this Congress (which extended from July 24 to 30 ) that it has been a complete success. A membership of about $75^{\circ}$ is an indication of the widespread interest taken in the subject, though an analysis of motives might reveal that the largeness of the number is partly due to other causes. In particular it can scarcely be doubted that the series of brilliant entertainments organised by the hospitality committee, under the secretaryship of Mrs. Alec Tweedie, was a bait which attracted many.

It may be useful to give some account of the general trend of opinion, judged partly by the views expressed by the speakers and partly by the behaviour of the audience, in an assembly of so many persons from so many countries, representing all those, with one or two exceptions, who hold that eugenics is a subject of serious importance.

The lead given by Mr. Balfour in his speech at the inaugural banquet in striking the keynote of diffidence and moderation was followed throughout the meeting. The application to human society of the methods found useful in the breeding pen is not advocated by the modern eugenist, neither does he wish to see permanently confined or castrated all those whom he considers undesirable mentally, morally, or physically. $\mathrm{He}$ does not plead for the repeal of all humanitarian legislation or for a return to "the good old days of natural selection."

$\mathrm{He}$ only urges that the possible eugenic or dyogenic results of fresh legislation may be seri- ously considered, and that the business of parenthood may be conducted by husbands and wives well informed as to their duties and regardful of their responsibilities to one another, to their children, and to the race. As a token of the feeling with regard to the latter point it may be mentioned that such phrases as "the dignity of motherhood" elicited applause as regularly as do the virtuous sentiments expressed by the heroine in melodrama.

Since the idea of practical eugenics was first mooted, its scope has naturally been much increased, so that there is room for a greater variety of views among those who pronounce a sort of general blessing on the eugenic ideal. This variety is expressed, for instance, in differences of opinion as to the relative importance of "nature" and "nurture." A regrettable result has been to debase the meaning of the word "eugenic," so that some speakers seemed to regard it as synonymous for "hygienic," whereas originally the two words were generally used in antithesis.

The presidential addiess by Major Leonard Darwin (which follows) was a worthy prelude to a series of papers many of which were of considerable interest and scientific importance. Among those which call for special mention are the following :-Mr. Raymond Pearl's paper on the inheritance of fecundity (in fowls); "La Fertilité des mariages suivant la profession et la situation sociale," by M. Lucien March, Directeur de la Statistique Générale de la France. M. March's work, based on the French census of 1906, adds materially to our knowledge of the subject in that he shows that although the rate of lower fertility in the higher social classes is generally true, exceptions frequently arise from the fact that other influences, such as the actual nature of the profession followed and the locality of domicile, produce definite and well-marked effects.

An admirable account was given by Mr. Bleecker van Wagenen of the preliminary report of the committee appointed by the Eugenic Section of the American Breeders' Association to study the best practical means for cutting off the defective germplasm of the human population. The eugenic legislation carried into effect by permitting or enforcing in certain cases specific sterilisation operations, in the several American States into which they have been introduced, was described, but not recommended. A considerable body of evidence as to the effect produced on the subject by such operations was summarised.

In conclusion, it must be said that heartiest congratulations are due to the president, Major Darwin, and to the secretary, Mrs. Gotto, on the organisation of the Congress. They have the satisfaction of knowing that the hard work involved has had its justification and reward in its successful issue. The Congress cannot fail to have a wide effect in promoting general knowledge of the aims of eugenists, and thus perhaps in meeting some of the undue criticisms which have been directed against them.

E. H. J. S.

NO. $223 \mathrm{I}$, VOL. 89] 
The following is the presidential address, delivered by Major Leonard Darwin :-

Thoughts suggestive of the general principle of evolution have been in the minds of many sages for many centuries. Not only have labourers in this field been found in all countries, but this great problem has been attacked from many different sides. Descartes and Leibnitz advanced from the basis of the physical sciences; Harvey viewed it as a physiologist; Kant and Spencer as philosophers; Goethe as a poet, and Lamarck and Darwin as naturalists, or in that field of science where our present beliefs were most recently accepted. And the result of this long struggle for mental victory on the part of these and other great men was unquestionably the practically universal acceptance of the principle of evolution in all fields of knowledge in the nineteenth century. For this great international achievement that epoch will ever remain famous.

And what is this belief which is now so widespread? It is indeed one which is so simple and now so interwoven with all our thoughts that we are apt altogether to overlook its existence. A belief in evolution merely implies a belief that all changes which have taken place and which are taking place in this world are changes in which effects follow causes in accordance with unvarying laws. It is one of the consequences of our belief in this principle, rather than an example of the belief itself, that we regard the earth as we now see it-the rocks, hills, and valleys-as having been produced by the action through long ages of those same natural forces which we can still see and study in operation to-day; a field of science in which Lyell was the great evolutionary pioneer. As regards living beings, the belief that a knowledge of the changes going on before our eyes gives the key to what has taken place in the past has in like manner led to the general acceptance of the view that all animals and plants are the descendants of some primitive form or forms from which they have been produced by some slow process of change. And this is indeed what the public now generally mean by evolution; although its essential feature is in reality to be found in the creed that all objects, animate and inanimate, are subject to the reign of natural law. Savages when they hear thunder hold that it is due to the fortuitous intervention of the thunder god; and when we, on the other hand, connect it with the generation in the air of electricity by friction or other natural processes, we are, in fact, asserting our belief in this underlying principle. And such a belief we now unhesitatingly avow whatever may be our creeds concerning the ultimate governance of the universe. Certainly it is in this spirit that all questions of fact in every field of science are now being investigated, and this is what is meant by the general acceptance of the principle of evolution.

But if the essential idea of this principle is indeed so simple, wherein, it may be asked, does its importance lie? The great value of the belief that similar effects always follow similar causes lies in the fact that we are thus stimulated to endeavour to understand what has taken place in the past, and that the knowledge thus acquired gives us some power of looking into the future. Daily forecasts of the weather are now issued, and these forecasts will obviously become more and more trustworthv as our knowledge of the natural laws affecting the air and the skies become more and more perfect. If we had remained faithful to the creed of the savage as to the incalculable nature of storms, we should now have no faith in these forecasts; or, in other words, without a belief in evolution, meteorologists would never have been stimulated NO. 223 I, VOL. 89] to make those scientific researches which have already so greatly increased our prophetic powers. And our present scientific creed is unquestionably acting in a similar way as regards the study of man and his social progress. Indeed, it now seems obvious that in a changing world our powers of foretelling the future-that is of making any forecast concerning the results of the forces now at work-must entirely depend on our knowledge of the sequence of events in the past. It is for this reason that we are attaching greater and greater importance to the study of the natural laws regulating the sequence of human events; for without any such knowledge we should in this world be marching blindfold into an unknown future. And it will in time be recognised that it is by increasing our prophetic powers that a belief in evolution has conferred its greatest benefits on mankind.

In order to make our knowledge of the evolutionary process practically useful, it is, therefore, obviously of the first importance that we should know how and why succeeding generations of mankind have resembled or differed from each other. The questions thus suggested for consideration may be divided under two main headings. In the first place it is to be noted that individually we pass on our learning and our thoughts to our juniors and our successors by writing and by word of mouth, whilst the material wealth of the nation in the form of improved surroundings is in a perpetual state of transference as time goes on. In other words, the environment of one generation is very largely dependent on the environment of the generations which preceded it; and according as we are increasing or dissipating the mass of accumulated knowledge, as we are careful or careless in the expression of our thoughts, as we add to or diminish the wealth of the nation, so is our conduct tending to make the world progressive or retrograde in this respect. No one can deny the importance of external conditions to the morals, health and comfort of mankind; and our instincts, selfish and unselfish, may be trusted to ensure a large amount of attention being always devoted to the factor of environment in the evolutionary process.

There is, however, on the other hand, another method by which each generation receives a heritage from its predecessors, and to which an adequate share of human thought has never as yet been given. With every increase in our scientific knowledge of the laws of life it becomes increasingly evident that the inborn qualities of the child are derived from its ancestors in accordance with laws which, though now but imperfectly known, are gradually but surely being brought to light. If the future is thus tied to the past in accordance with these laws of heredity, we must be entirely dependent on our knowledge concerning them when endeavouring to ascertain whether the inherent qualities of the individuals composing the coming generations will show an improvement or the reverse in comparison with our standards of to-day; and, when thus peering into the future, it is therefore evident that a mere study of the factors directly and immediately affecting our present environment, however important it may be, is wholly insufficient for our needs. There are, in fact, two great factors influencing us all through our lives, heredity and environment; and if at this congress we are chiefly concerned with the former-that is with nature rather than with nurture-it must not be assumed that little importance is attached by us to the many endeavours now being made to improve the environment of the people, an object unquestionably greatly worth striving for. If we choose natural inheritance as the field for our operations, it is partly because it is not wise to attempt to cover too much ground on 
one occasion, and partly because this branch of inquiry into human aflairs, being surrounded with many difficulties and having been much neglected in the past, seems now to be the one most in need of our efforts. Then, again, not only are the careers of all men largely influenced by their inborn qualities, but the surroundings which each man steps into at his birth undoubtedly in large measure depend-indeed in so far as they are under human control perhaps wholly depend-on the inborn qualities of those of their ancestors and predecessors who were instrumental in moulding that environment. Thus any steps which we may now take tending to improve the racial characteristics of the generations of the immediate future will undoubtedly benefit the countless millions of the more distant future as regards the heritage they will receive at birth in the form, not only of inborn qualities, but also of improved surroundings. To endeavour both to study the laws of heredity and practically to apply the knowledge thus acquired to the regulation of our lives, seems, therefore, to be a paramount duty which we owe to posterity.

But when we embark on such a comprehensive study of life as is here suggested, it soon becomes apparent that the history of the world is not a tale of a continuous and uninterrupted advance. Nature seems to have been making innumerable experiments, of which many proved to be failures. New species have often arisen in the long bygone ages merely, it would seem, to become extinct and to leave no living traces behind them. New civilisations have arisen from time to time and have then died away, leaving the world little or no better for the progress thus temporarily made. It is true, no doubt, that, if we take a wide enough field of view, it does appear that the world has always been slowly advancing towards a better state of things, and the teachings of science need not shalke the faith that some of us hold, that this advance is destined to continue in the future. But if we confine our view within a narrower horizon, and if we look merely at our own form of civilisation, the history of the past affords us no right whatever to prophesy a continued improvement in the lot of our race in the immediate future-no, not even the right to deny the possibility of the decadence of any nation. In fact, pride in our past achievements must not make us turn a deaf ear to the warnings which come from a study of the laws of heredity. Indeed, many circumstances brought to light in recent investigations ought to force us to consider whether the progress of Western civilisation is not now at a standstill, and, indeed, whether we are not in danger of an actual retrograde movement.

No doubt we are ignorant in many respects concerning the laws under which evolution has been operative in the past. We are especially ignorant about the final causes of variations in animals and plants, and also about the effects produced by environment on the racial qualities of future generations; and there may therefore be forces now at work making for racial progress or decay of which we know nothing. There is, however, certainly one agency which has had a great influence in the past and of which much is now known, and that is natural selection, or nature playing the part of the breeder of cattle in refusing to breed from inferior stocks. This progressive agency, by continually weeding out the unfit, has always tended to make living beings more and more able to seize the opportunities offered to them by their environments. And it seems as if this forward movement had gone on during all the Iong ages since life first appeared on earth until recent times, when by our social methods we have been doing our best to prevent further progress being made by this same means. The unfit amongst men are noiv no longer necessarily killed off by hunger and disease, but are cherished with care, thus being enabled to reproduce their kind, however bad that kind may be. It is true that we cannot but glory in this saving of suffering; for the spirit which leads to the protection of the weak and afflicted is of all things that which is the best worth preserving on earth; and we can therefore never voluntarily go back to the crude methods of natural selection. But we must not bline ourselves to the danger of interfering with nature's ways, and we must proclaim aloud that to give ourselves the satisfaction of succouring our neighbours in distress without at the same time considering the effects likely to be produced by our charity on future generations is, to say the least, but weakness and folly.

The filling up of the blanks in our knowledge of the laws of life ought undoubtedly always to stand in the forefront of our programme. But our ignorance certainly does not forbid us to inquire whether our present knowledge is not sufficient to enable some steps to be taken with the view of safeguarding the race from the evil effects likely to be felt in the future as the results of our existing social policy. Certainly Sir Francis Galton, whose name we hope will ever in future be associated with the science of eugenics, a science to which he devoted the best years of his long life, declared with no uncertain voice that something should be attempted without further delay. The necessity for some action now being taken can, indeed, no longer be denied on account of the absence of witnesses, non-scientific as well as scientific, in its favour. If we tell the breeders of cattle that their knowledge of the laws of heredity is so imperfect that it is useless for them either to attempt to avoid breeding from their worst stocks or to try only to breed from their best stocks, why, they would simply laugh at us; and the number of those who now see matters as regards mankind in the same light is steadily increasing No doubt the paramount necessity of maintaining a moral code introduces vast difficulties in the case of man which are unknown in the stock vard, and unquestionably the possibilities open to us are thus greatly limited. No doubt also our ignorance imperatively commands us to be cautious in our advance. But stagnation is to be feared as well as error; and when we see good reason to believe that some step could now be taken tending to benefit future generations, both as regards their minds and their bodies, our fears must not be allowed to stand too much in the way of our actions.

It must, however, be remembered that it is not sufficient to satisfy the students of biolog! and sociology in order to ensure the adoption of the needed reforms; for the knowledge which has convinced experts must be widely disseminated before it can produce this result. Again to adopt the analogy of the weather, the knowledge of the meteorologist, even if it should make him a perfect prophet, would be useless for practical purposes if his forecasts merely remained on record in his laboratory for his own edification. The elaborate system of telegraphing the weather forecasts all over the country is essential if the sailor and the farmer are to have any chance of utilising them practically. In the same way, our knowledge of the laws of heredity, however perfect it may become, will continue to be of comparatively little use as a method of ensuring the progress of mankind until it is not only widely known but actually incorporated in the moral code of the people. The man of science is right in regarding truth as a mistress to be sought for her own sake only, for in that 
way, certainly, she is most likely to be captured. But it must not be forgotten that the results of the labours of many sages during many centuries will continue to be of no value to mankind in general so long as evolution is merely regarded as a principle by which to interpret the past. We must have a bridge to unite the domain of science with the domain of human action, and such a bridge forms an essential part of the structure of eugenics. Both national societies and international cooperation are needed for the purpose of spreading the light, and the efforts already made in these directions will, it is hoped, be furthered by the holding of this congress.

We may thus conclude that though for the moment the most crying need as regards heredity is for more knowledge, yet we must look forward to a time when the difficulties to be encountered will be moral rather than intellectual; and against moral reform the demons of ignorance, prejudice, and fear are certain to raise their heads. But the end we have in view, an improvement in the racial qualities of future generations, is noble enough to give us courage for the fight. Our first effort must be to establish such a moral code as will ensure that the welfare of the unborn shall be held in view in connection with all questions concerning both the marriage of the individual and the organisation of the State. As an agency making for progress, conscious selection must replace the blind forces of natural selection; and men must utilise all the knowledge acquired by studying the process of evolution in the past in order to promote moral and physical progress in the future. The nation which first takes this great work thoroughly in hand will surely not only win in all matters of international competition, but will be given a place of honour in the history of the world. And the more nations there are who set out on this path, the more chance there is that some of them will run this course to the end. The struggle may be long and the disappointments may be many. But we have seen how the long fight against ignorance ended with the triumphant acceptance of the nrinciple of evolution in the nineteenth century. Eugenics is but the practical application of that principle, and may we not hope that the twentieth century will, in like manner, be known in future as the century when the eugenic ideal was accepted as part of the creed of civilisation? It is with the object of ensuring the realisation of this hope that this congress is assembled here to-day.

\section{NOTES.}

A Rovil Commission has been appointed to report on the means of supply and storage of liquid fuel in peace and war and its applications to warship engines, whether indirectly or by internal combustion. The following are to be the members of the Commission :Lord Fisher of Kilverstone, O.M. (chairman), the Right Hon. George Lambert, M.P., Sir Boverton Redwood, Bart., Sir Philip Watts, K.C.B., F.R.S., Sir H. J. Oram, K.C.B., F.R.S., Sir J. R.. Jellicoe, K.C.B., Sir W. Matthews, K.C.M.G., Sir T. H. Holland, K.C.I.E., F.R.S., Sir T. E. Thorpe, C.B., F.R.S., Mr. A. Gracie, Mr. H. O. Jones, and Mr. A. F. Yarrow. The joint secretaries will be Captain P. W. Dumas, R.N., Engineer-Lieutenant C. J. Hawkes, R.N., and Mr. J. H. Narbeth.

Mr. E. H. 'Tennyson d'Eyncourt has been appointed Director of Naval Construction to the Admiralty, and Mr. W. H. Whiting Superintendent of

$$
\text { NO. } 223 \text { I, VOL. 89] }
$$

Construction Accounts and Contract Work, in succession respectively to Sir Philip Watts, K.C.B., F.R.S., and Sir W. E. Smith, C.B., who are retiring. Mr. W. J. Berry becomes Assistant Director of Naval Construction. Sir Philip Watts is to be retained as Adviser on Naval Construction.

Commander Evans, R.N., second in command, under Captain Scott, of the British Antarctic Expedition, is expecting to leave England at the end of August for New Zealand, where he will resume command of the Terra Nova, which will proceed to the south polar regions to meet Captain Scott and his party.

A Reuter message has been received stating that Captain Mikkelsen and Mr. Iversen, who in the summer of 1909 set out to discover the depôt of $\mathrm{Mr}$. M. Erichsen and his two companions, who perished in the expedition of $1907-8$, have arrived at Aalesund, and will proceed shortly to Copenhagen. The two explorers, who had not been heard of since they left the expedition on April 10, I910, on the 76 th parallel north latitude, proceeded over the inland ice to Denmark Firth, where they found a record left by Erichsen. On May 29, I910, they began the return journey. They were subjected to terrible hardships. The dogs died one after the other, and they were obliged to shoot the few remaining animals for food. On November 29, I9lo, Shannon Island was reached, where they hoped to meet Norwegian whaling boats in the summer of $191 \mathrm{I}$, but the hope was vain. Having waited through the summer until it was so late in the year that no whaling boats could be expected, they left Shannon Island and went to Shamrock Island, where they wintered. Here the Norwegian fishing vessel Sjöblomsten found them, after they had abandoned all hope, and brought them to Aalesund. According to a statement made by Captain Mikkelsen, two reports from the late Mylius Erichsen were found in Denmark Firth. The first, dated September I2, stated that he was returning along the coast with provisions for sixteen days, while the second report, found in a summer camp, spoke of his discoveries, among which was one that the Peary Channel did not run through from sea to sea behind Hazen and Heilprin Lands, and that Navy Cliff was connected with Heilprinland. Erichsen's diaries were also recovered from Skærgaardsfjord.

THE report of the Court of Inquiry, presided over by Lord Mersey, on the loss of the Titanic was presented at a final sitting of the Court on Tuesday last. The finding is as follows:-The Court, having carefully inquired into the circumstances of the abovementioned shipping casualty, finds, for the reasons appearing in the annex hereto, that the loss of the said ship was due to collision with an iceberg, brought about by the excessive speed at which the ship was being navigated. This finding, and the report itself, are concurred in by the five assessors:-Rear-Admiral the Hon. S. A. Gough-Calthorpe, Captain A. W. Clarke, Commander F. C. A. Lyon, Prof. J. H. Biles, and $\mathrm{Mr}$. E. C. Chaston. 